\title{
Comparison of Various Platforms in Cloud Computing
}

\author{
Subasish Mohapatra \\ Department of Computer \\ Science and Application \\ College of Engineering and Technology \\ Bhubaneswar, Odisha, India \\ Shradha Pattanayak \\ Department of Computer \\ Science and Application \\ College of Engineering and Technology \\ Bhubaneswar, Odisha, India
}

\author{
Subhadarshini Mohanty \\ Department of Computer \\ Science and Application \\ College of Engineering and Technology \\ Bhubaneswar, Odisha, India \\ Arunima Hota \\ Department of Computer \\ Science and Application \\ College of Engineering and Technology \\ Bhubaneswar, Odisha, India
}

\begin{abstract}
Clouds are a large volume of virtualized resources which are easy to use and access. It is a platform providing dynamic pool resources and virtualization. Based on a pay-as-you-go model, it enables hosting of pervasive applications from consumer, scientific and business domains. Cloud computing is the emerging internet based technology which emphasizes commercial computing. Cloud computing can be classified as a new paradigm for the dynamic provisioning of computing services supported by state-of-art data centers that usually employ virtual machine (VM) technologies for the consolidation and environment isolation purposes [1]. In this work, the comparison between the different cloud computing platforms such as Abicloud, Eucalyptus, XCP, Nimbus, OpenNebula, and Tplatform is presented. The basic principles are outlined of all the above mentioned platforms and the architectural tradeoffs of those platforms are discussed.
\end{abstract}

\section{Keywords}

Cloud computing, Abicloud, Eucalyptus, XCP, Nimbus, Open nebula, Tplatform

\section{INTRODUCTION}

Cloud computing is fundamentally satisfying the expectations for how and when computing, storage, and networking resources should be allocated, managed, consume and allow the user to utilize services globally. It is the development of parallel computing, distributed computing, and grid computing and it is the combination of virtualization, software-as-a-service (SaaS), infrastructure-as-a-service (IaaS) and platform- as-a-service (PaaS) [2] which are demanded by various organizations. A web browser or a light-weight desktop or mobile application is required for accessing cloud-based applications by end users. Servers at a remote location are required to store business software and user's data [3]. In the cloud, computing virtualization occurs on several levels. There are various platforms to set up cloud computing infrastructure taken in today's market but it has to be taken into consideration so that the infrastructure is flexible, secure to display various applications natural features of computations and IT services deliverance which allows testing of IT capability [4,5]. Hence different platforms are developed to manage the public, private and hybrid cloud. Some key benefits of cloud computing include hiding and abstraction of complexity, virtualized resources and efficient use of distributed resources [22]. Some examples of emerging cloud computing platforms are Amazon EC2, IBM Blue Cloud etc [23, 24].

\section{CLOUD SERVICE MODELS}

According to NIST cloud computing is a model for enabling ubiquitous, convenient, on-demand network access to a shared pool of configurable computing resources that can be rapidly provisioned and released with minimal management effort or service provider interaction. Cloud computing provides on demand self-service, broad network access, resources pooling, rapid elasticity, measured service etc. Cloud computing supports 3 service models such as

\subsection{Software as a Service (SaaS)}

SaaS sometimes referred to as "Software on demand", which is a software that is connected to the internet to run on the firewall or personal computer. The applications are accessible from various client devices through either a client interface such as web browser. The examples of SaaS are email, CRM, ERP etc. In 2010 SaaS sales reached 10 billion and increased to 12.1 billion in 2011 i.e. $20.7 \%$ up from 2010.CRM leads to be the largest market for Sass [6]. SaaS based on the multitenant architecture. This model enables all customers to use single version application with a single configuration.

\subsection{Platform as a Service (PaaS)}

PaaS facilitates the delivery of a computing platform and solution stack as a service. PaaS offers deployment of applications by reducing the cost and complexity of buying and maintaining hardware, software and provisioning hosting capabilities [7]. PaaS also provides application services such as team collaboration, web service integration and marshaling, database integration, security, scalability, storage, persistence, application instrumentation and developer community facilitation. These services may be referred to as an integrated solution over the web. PaaS offers to create a composition of multiple web services. These services access databases and reuse services maintained inside private networks.

\subsection{Infrastructure-as-a-Service (IaaS)}

Infrastructure is the backbone of cloud computing. In IaaS the capability provided to the consumer is to provision processing, storage, networks and other fundamental computing resources where the consumer is able to deploy and run arbitrary software which includes operating systems and applications. IaaS delivers computer infrastructure typically a platform virtualization environment as a service. IaaS eliminate the need for administration and maintenance of hardware. It enterprises grade infrastructures for all subscribers. IaaS provides images in a virtual machine, imagelibrary, file-based storage, firewalls, load balancers, IP 
addresses, software bundles etc. Examples of Iaas are Amazon Ec2, HP cloud, Joyent, Google compute engine etc [8].

\section{VARIOUS CLOUD COMPUTING PLATFORMS \\ 3.1 AbiCloud}

AbiCloud is a cloud computing platform. It can be used to build, integrate and manage public as well as private cloud in the homogeneous environments. Using AbiCloud, user can easily and automatically deploy and manage the server, storage system, network, virtual devices and applications and so on. Using AbiCloud, user can finish deploying a new service by just dragging a virtual machine with mouse [9].This is easier and reliable than other cloud platforms. It can also manage Ec 2 according to the rules of protocol.

\subsection{Eucalyptus}

It is an open source private cloud platform for cloud computing that implements infrastructure as a service. Eucalyptus is open source private cloud software for building private and hybrid clouds that are compatible with AWS APIs. With AWS-compatibility, the open source software pools together existing virtualized infrastructure to create private or hybrid cloud resources for compute, network, and storage. Eucalyptus uses the terminologies like images, instances, and IP addressing, security, networking and access control.

\subsection{Xen Cloud Platform (XCP)}

The Xen hypervisor is a solution for infrastructure virtualization that provides an abstraction layer between server's hardware and the operating system. A Xen hypervisor allows each physical server to run several "virtual servers" handling the operating system and its applications from the underlying physical server. The Xen solution is used by many cloud solutions such as Amazon Ec2, Nimbus and Eucalyptus. Xen.org invented Xen cloud platform (XCP) as a solution for cloud infrastructure virtualization. But, differently from existent open source cloud solutions, XCP does not provide the overall architecture for cloud services. Their goal is to provide a tool to cope with automatic configuration and maintenance of cloud platforms.

\subsection{Nimbus}

Nimbus is an open source solution to turn clusters into an infrastructure as a service (IaaS) for cloud computing mainly on scientific applications.

To deploy applications, Nimbus offers a "cloud kit" configuration that consists of a manager service hosting and an image repository. Nimbus leaves most of the customization to the administrator and not to the user and has several more components which are constants. Nimbus is very flexible in the number and types of virtual networks that can be set fewer of those options pertain to the nitty-gritty of the underlying software stack.

\subsection{Open Nebula}

Open Nebula is an open source toolkit to build private, public and hybrid clouds. It has been designed to be integrated with networking and storage solutions and to fix into existing datacenters. It allows user deploy and manage virtual machines on physical resources and it can set user's data centers or clusters to flexible virtual infrastructure that can automatically adapt to the change of the service load. The main difference of Open Nebula and Nimbus is that Nimbus implements remote interface based on EC2 or WSRF through which user can process all security related issues, while open nebula does not[13].

The Open Nebula architecture based on the three basic technologies to enable the provision of services on a distributed infrastructure: virtualization, storage and network.

\subsection{Tplatform}

Tplatform is a cloud solution that provides a development platform for web mining applications, which is inspired in Google cloud technologies and which acts as a platform as a service (PaaS). Their infrastructure is supported by three technologies: a scalable file system called Tianwang File System (TFS) which is similar to the Google File System (GFS), the big table data storage mechanism and the map reduce programming model.

\section{ISSUES IN CLOUD COMPUTING}

Cloud Computing can be defined as a pool of virtualized computing resources that allows users to gain access to applications and data in a web based environment on demand. Clouds computing still have some issues [14]:

\subsection{Attacks targeting shared-tenancy environment}

Virtual Machine (VM) is software which runs in its own operating system. But multiple virtual machines can concurrently run in different software applications i.e. in different operating systems but on a single physical machine. Hence user's personal data may be scattered in various virtual data centers rather than stay in same physical location. Hence when the users accessing the services some data may be leaked which is accessed by the attackers. Hence privacy is the major issue in cloud computing.

\subsection{Security Issues}

Some issues such as data loss, phishing, botnet are the serious issues to an organization's data. The issue of 'reputation fatesharing' will severely damage the reputation of many good cloud citizens, who shares the cloud computing resources [8].

\subsection{Issues Regarding SaaS and PaaS}

A group of experts in the field of data mining raises the issue of establishing a data mining standard on the cloud, with a particular focus on the practical use of statistical algorithms, the integration of predictive analysis across different data mining based SaaS clouds [9]. It would be more difficult to reach the uniformity the way cloud computing developed in accordance with SaaS and PaaS [19].

\subsection{Flexibility and other Issues}

Here flexibility is measured in terms of reliability i.e. the issues with the cloud server, which means sometimes the cloud servers slowdowns like our normal server. Apart from that some other legal issues like confidentiality of individual all the way through various levels.

\subsection{Issues Regarding Data Storage}

This issue simply called freedom of users i.e. cloud computing doesn't allow users to physically access the storage of data and control the hands of the cloud providers by leaving the data storage. 


\section{COMPARISON BETWEEN THE} DIFFERENT PLATFORMS

\begin{tabular}{|c|c|c|c|c|c|c|}
\hline Feature & AbiCloud & Nimbus & Open Nebula & Eucalyptus & Xcp & Tplatform \\
\hline Service & Iaas & IaaS & IaaS & IaaS & SaaS & $\mathrm{PaaS}$ \\
\hline Load balancing & $\begin{array}{l}\text { Abiquo v2.6, } \\
\text { simplicity } \\
\text { and } \\
\text { functionality } \\
\text { were the } \\
\text { focus and the } \\
\text { workflow } \\
\text { acceptance } \\
\text { tool has } \\
\text { achieved just } \\
\text { that. }\end{array}$ & $\begin{array}{l}\text { Launches } \\
\text { self- } \\
\text { configuring } \\
\text { virtual } \\
\text { cluster. }\end{array}$ & $\begin{array}{lr}\text { Nginx } & \text { Server } \\
\text { configured as load } \\
\text { balancer, used round } \\
\text { robin }\end{array}$ & $\begin{array}{l}\text { Simple load } \\
\text { balancing } \\
\text { cloud } \\
\text { controller }\end{array}$ & $\begin{array}{l}\text { XCCS Load } \\
\text { balancer is used for } \\
\text { minimizing the risk }\end{array}$ & $\begin{array}{l}\text { Distributed } \\
\text { service } \\
\text { integrate } \\
\text { with Google } \\
\text { cloud } \\
\text { platform }\end{array}$ \\
\hline \multirow[t]{2}{*}{ Fault tolerance } & $\begin{array}{l}\text { FTM is used } \\
\text { for fault } \\
\text { tolerance } \\
\text { mechanism }\end{array}$ & $\begin{array}{l}\text { Checking } \\
\text { worker } \\
\text { nodes } \\
\text { periodically } \\
\text { and } \\
\text { recovery }\end{array}$ & $\begin{array}{l}\text { The daemon can be } \\
\text { restarted and all the } \\
\text { running } \\
\text { recovered }\end{array}$ & $\begin{array}{l}\text { Separate } \\
\text { cluster } \\
\text { within the } \\
\text { Eucalyptus } \\
\text { cloud } \\
\text { reduce the } \\
\text { chance of } \\
\text { correlated } \\
\text { failure }\end{array}$ & $\begin{array}{l}\text { Kemari is used for } \\
\text { fault tolerance } \\
\text { mechanism. }\end{array}$ & $\begin{array}{l}\text { Works with } \\
\text { both } \\
\text { modules } \\
\text { and network } \\
\text { interfaces } \\
\text { for } \\
\text { balancing } \\
\text { the system }\end{array}$ \\
\hline & $\begin{array}{ll}\text { Not } & \text { support } \\
\text { EC2 } & \end{array}$ & $\begin{array}{l}\text { Support } \\
\text { EC2 }\end{array}$ & Open,multi-platform & $\begin{array}{l}\text { Support } \\
\text { Ec2,S3 }\end{array}$ & Support in EC2 & $\begin{array}{l}\text { Support } \\
\text { EC2-VPC }\end{array}$ \\
\hline Security & $\begin{array}{l}\text { The } \\
\text { integration of } \\
\text { VNS3 with } \\
\text { Abiquo's } \\
\text { platform also } \\
\text { allows users } \\
\text { to control } \\
\text { SDN } \\
\text { capabilities, } \\
\text { and provide } \\
\text { flexibility } \\
\text { and } \\
\text { additional } \\
\text { security } \\
\text { within the } \\
\text { rigor and } \\
\text { management } \\
\text { of the service } \\
\text { provider's } \\
\text { standard } \\
\text { offers. }\end{array}$ & $\begin{array}{l}\text { PKI } \\
\text { credential } \\
\text { required }\end{array}$ & $\begin{array}{l}\text { Firewall, } \\
\text { private }\end{array}$ & $\begin{array}{l}\text { WS security } \\
\text { for } \\
\text { authenticati } \\
\text { on, cloud }\end{array}$ & $\begin{array}{lcc}\text { Uses } 0.1 & \text { user } \\
\text { security for } & \text { user } \\
\text { authentication } & \end{array}$ & $\begin{array}{l}\text { Hadoop-like } \\
\text { infrastructur } \\
\text { e system. } \\
\text { Contribute } \\
\text { to TPlatfor } \\
\text { m developm } \\
\text { ent by } \\
\text { creating an } \\
\text { account on } \\
\text { GitHub. }\end{array}$ \\
\hline Reliability & - & $\begin{array}{l}\text { The current } \\
\text { supported } \\
\text { protocols } \\
\text { are Web } \\
\text { Services } \\
\text { based or } \\
\text { HTTP } \\
\text { based. They } \\
\text { all run in } \\
\text { either } \\
\text { an Apache } \\
\text { Axis based } \\
\text { Java } \\
\text { container }\end{array}$ & $\begin{array}{l}\text { Rollback host and } \\
\text { VM }\end{array}$ & $\begin{array}{l}\text { S } \\
\text { implements } \\
\text { the industry- } \\
\text { standard } \\
\text { AWS } \\
\text { API for on- } \\
\text { premise } \\
\text { cloud } \\
\text { infrastructur } \\
\text { e }\end{array}$ & $\begin{array}{l}\text { Corrosion } \\
\text { Protection fluid is } \\
\text { used for direct and } \\
\text { easy application }\end{array}$ & $\begin{array}{l}\text { powerful, } \\
\text { easy-to- } \\
\text { deploy, } \\
\text { enterprise- } \\
\text { capable, } \\
\text { integrated } \\
\text { reliability } \\
\text { solution. }\end{array}$ \\
\hline
\end{tabular}




\begin{tabular}{|c|c|c|c|c|c|c|}
\hline & & $\begin{array}{l}\text { or Apache } \\
\text { CXF. }\end{array}$ & & & & \\
\hline $\begin{array}{l}\text { Transplant } \\
\text { ability }\end{array}$ & Easy & Common & Common & Common & Common & Easy \\
\hline VM support & $\begin{array}{l}\text { Virtual } \\
\text { Box,Xen,VM } \\
\text { ware,VM }\end{array}$ & Xen & Xen,VMware & $\begin{array}{l}\text { Xen,VMwar } \\
\text { e,KVM }\end{array}$ & Debian Etch & $\begin{array}{l}\text { HVM suppo } \\
\text { rt (Intel VT } \\
\text { or AMD-V) }\end{array}$ \\
\hline $\begin{array}{l}\text { Virtualization } \\
\text { management }\end{array}$ & $\begin{array}{l}\text { Abiquo } \\
\text { virtualization }\end{array}$ & $\begin{array}{l}\text { Xen } \\
\text { Virtualizatio } \\
n\end{array}$ & $\begin{array}{l}\text { Xen KVM and on- } \\
\text { demand access to } \\
\text { Amazon EC2 }\end{array}$ & $\begin{array}{l}\text { Xen } \\
\text { hypervisor }\end{array}$ & Xen virtualization & $\begin{array}{l}\text { VMware } \\
\text { virtualizatio } \\
\mathrm{n}\end{array}$ \\
\hline Storage & $\begin{array}{l}\text { Abi cloud } \\
\text { appliance } \\
\text { manager }\end{array}$ & $\begin{array}{l}\text { Grid FTP \& } \\
\text { SCP }\end{array}$ & $\begin{array}{l}\text { SQLite3 backend is } \\
\text { the core component of } \\
\text { the open nebula } \\
\text { internal data } \\
\text { structures. }\end{array}$ & $\begin{array}{l}\text { Walrus is } \\
\text { used for the } \\
\text { front end } \\
\text { storage } \\
\text { system }\end{array}$ & $\begin{array}{ll}\text { Sxm(Storage } & \text { X } \\
\text { motion),Xcp 1.6 } & \end{array}$ & ---- \\
\hline $\begin{array}{l}\text { Development } \\
\text { Language }\end{array}$ & $\begin{array}{l}\text { Ruby++,Pyth } \\
\text { on }\end{array}$ & Java & Java & Java & Java,C++ & Java \\
\hline Os Support & Linux & Linux & Linux & $\begin{array}{l}\text { Linux, } \\
\text { windows } \\
\text { vms }\end{array}$ & Linux & Linux \\
\hline $\begin{array}{l}\text { Cloud } \\
\text { character }\end{array}$ & $\begin{array}{l}\text { Public/Privat } \\
\mathrm{e}\end{array}$ & Public & Public & $\begin{array}{l}\text { Private and } \\
\text { hybrid }\end{array}$ & Public & Public \\
\hline Scalability & Scalable & Scalable & Dynamic, Scalable & Scalable & Scalable & Scalable \\
\hline Architecture & $\begin{array}{l}\text { Managing } \\
\text { complexity, } \\
\text { Delivering } \\
\text { simplicity, } \\
\text { distributed } \\
\text { installation }\end{array}$ & $\begin{array}{l}\text { Client side } \\
\text { cloud } \\
\text { computing } \\
\text { interface to } \\
\text { globus- } \\
\text { enabled } \\
\text { teraport } \\
\text { cluster }\end{array}$ & $\begin{array}{l}\text { Based on Haizea } \\
\text { scheduling }\end{array}$ & $\begin{array}{l}\text { Ability to } \\
\text { combine } \\
\text { multiple } \\
\text { clusters into } \\
\text { a single } \\
\text { cloud by } \\
\text { private } \\
\text { cloud. }\end{array}$ & $\begin{array}{l}\text { A special domain, } \\
\text { called domain } 0 \\
\text { contains the drivers } \\
\text { for all the devices in } \\
\text { the system. }\end{array}$ & $\begin{array}{l}\text { Six degrees } \\
\text { group's } \\
\text { cloud } \\
\text { hosting is } \\
\text { delivered on } \\
\text { a resilient, } \\
\text { geographica } \\
\text { lly } \\
\text { datacenter } \\
\text { space. }\end{array}$ \\
\hline Infrastructure & Xen & $\begin{array}{l}\text { Xen } \\
\text { hypervisor } \\
\text { and KVM }\end{array}$ & Xen hypervisor & $\begin{array}{l}\text { Xen } \\
\text { hypervisor } \\
\text { and KVM }\end{array}$ & Xen & $\begin{array}{l}\text { TFS,Big } \\
\text { Table and } \\
\text { Map reduce }\end{array}$ \\
\hline Used By & $\begin{array}{l}\text { Abi Cloud } \\
\text { Project }\end{array}$ & $\begin{array}{l}\text { Brook have } \\
\text { National } \\
\text { labs }\end{array}$ & Cumulus Project & UEC & XCP community & $\begin{array}{l}\text { Tplatform } \\
\text { Project }\end{array}$ \\
\hline $\begin{array}{l}\text { Main } \\
\text { Characters }\end{array}$ & $\begin{array}{l}\text { Used to } \\
\text { integrate } \\
\text { private and } \\
\text { public cloud }\end{array}$ & $\begin{array}{l}\text { Aims to turn } \\
\text { legacy } \\
\text { clusters into } \\
\text { Iaas clouds }\end{array}$ & $\begin{array}{l}\text { Policy driven resource } \\
\text { allocation }\end{array}$ & $\begin{array}{l}\text { Hierarchical } \\
\text { architecture }\end{array}$ & $\begin{array}{ll}\text { Only tool for } \\
\text { automatic } \\
\text { maintenance } \\
\text { clouds }\end{array}$ & $\begin{array}{l}\text { Focus on } \\
\text { web text } \\
\text { mining } \\
\text { applications }\end{array}$ \\
\hline Web interface & Libvirt & $\begin{array}{l}\text { Ec2,WSDL, } \\
\text { WSRF }\end{array}$ & $\begin{array}{l}\text { Libvirt,OCCI,EC2,AP } \\
\text { I }\end{array}$ & $\begin{array}{l}\text { Auto } \\
\text { scaling(Am } \\
\text { azon EC2) }\end{array}$ & $\mathrm{Xm}$ CLI $(\mathrm{Xe}, \mathrm{Xl})$ & $\begin{array}{l}\text { Cloud stack } \\
\text { (AWS } \\
\text { EC2,S3) }\end{array}$ \\
\hline
\end{tabular}

\section{ISSUES IN CLOUD COMPUTING}

Cloud Computing can be defined as a pool of virtualised computing resources that allows users to gain access to applications and data in a web based environment on demand. Clouds computing still have some issues [14]:

\subsection{Attacks targeting shared-tenancy environment}

Virtual Machine (VM) is software which runs in its own operating system. But multiple virtual machines can concurrently run in different software applications i.e. in different operating systems but on a single physical machine. Hence user's personal data may be scattered in various virtual data centers rather than stay in same physical location. Hence when the users accessing the services some data may be leaked which is accessed by the attackers. Hence Privacy is the major issue in cloud computing.

\subsection{Security Issues}

Some issues such as data loss, phishing, botnet are the serious issues to an organization's data. The issue of 'reputation fate- 
sharing' will severely damage the reputation of many good cloud citizens, who shares the cloud computing resources [8].

\subsection{Issues Regarding SaaS and PaaS}

A group of experts in the field of data mining raises the issue of establishing a data mining standard on the cloud, with a particular focus on the practical use of statistical algorithms, the integration of predictive analysis across different data mining based SaaS clouds [9]. It would be more difficult to reach the uniformity the way cloud computing developed in accordance with SaaS and PaaS [19].

\subsection{Flexibility and other Issues}

Here flexibility is measured in terms of reliability i.e. the issues with the cloud server, which means sometimes the cloud servers slowdowns like our normal server. Apart from that some other legal issues like confidentiality of individual all the way through various levels.

\subsection{Issues Regarding Data Storage}

This issue simply called freedom of users i.e. cloud computing doesn't allow users to physically access the storage of data and control the hands of the cloud providers by leaving the data storage.

\section{APPLICATIONS OF CLOUD COMPUTING}

The National Institute of standards and Technology defines Cloud Computing as a model for enabling convenient, Ondemand network access to a shared pool of configurable computing resources [10]. PaaS offers deployment of applications by reducing the cost and complexity of buying and maintaining hardware and software and provisioning hosting capabilities [11].The PaaS services offers scalability and maintenance [12].There are some applications of cloud computing such as:

1. Cloud Computing provides a scalable online environment which facilitates the ability to handle an increased volume of work without impacting on the performance of the system.

2. Cloud computing offers significant computing cap ability and economy of scale that might not otherwise be affordable to business, especially small and medium enterprises.

3. Cloud Computing avoid the expense and time consuming task of installing and maintaining hardware infrastructure and software applications.

4. Cloud Computing allow for the rapid provisioning and use of services to clients by optimizing their IT infrastructure.

5. Cloud Computing provides infinite possibility for the users to use internet.

6. It provides secure data storage center.

7. It supports development languages like Java, Ruby, C++, Python etc.

8. It provides easy transplant-ability.

9. It provides IaaS, PaaS and SaaS cloud form.

10. It provides continuity in the event of a site failure during external hosting.

\section{CHALLENGES OF CLOUD COMPUTING}

The current adoption of cloud computing is associated with numerous challenges. Cloud Computing is still passing its infancy stage, there are many challenging issues waiting for tackling [18].Based on the Survey conducted by IDC in 2008 [15] the major challenges of the cloud computing are:

\subsection{Security}

Security issue played the vital role in the cloud computing acceptance. Hence some security issues such as data loss, phishing, and botnet (running remotely on a collection of machines) pose serious threats to organization's data and software. The multi-tenancy model and the pooled computing resources(hard disk, virtual machine) in cloud computing has organized to new security challenges which requires some novel technologies to tackle with i.e. the resources on the same physical machine invites unexpected side channels between a malicious resource and regular resource[16].

\subsection{Costing Model}

Cloud Computing platform utilize the virtualization technology to transparently and dynamically supply virtual computing and storage resources for the satisfaction of user's different requirements according to the relative scheduling strategies[17]. It is clear that cloud consumers must consider the tradeoffs amongst computation, communication and integration. Due to migration cloud can significantly reduce the infrastructure cost, which raise the cost of transferring an organization's data to and from public \& community cloud is higher.

\subsection{Charging Model}

The role of open source cloud computing is to build some mechanism [20]. From SaaS cloud providers, the cost of developing multi tenancy within their offering can be very substantial which includes redesign \& redevelopment of software. Hence from the cloud providers, the elastic resource pool has made the cost analysis is a lot more complicated than regular data centers, which calculates their cost on consumptions on static computing.

\subsection{Service Level Agreement (SLA)}

Cloud consumers do not have control over the resources like quality, availability, reliability and performance i.e. it is very much important for consumers to obtain guarantees from the providers on service delivery. Hence these are provided through service level agreements (SLAs), which are negotiated between the providers and consumers. In addition, different cloud characters (IaaS, PaaS, and SaaS) will need to define SLA, which also raises a no. of implementation problems for the cloud providers.

\subsection{Cloud Interoperability Issue}

Hazy Cloud phenomenon severely hinders the development of cloud ecosystems by forcing vendor locking, which prohibits the ability of users to choose from alternative offering simultaneously in order to optimize the resources at different levels within an organization. Hence a number of recent works address the interoperability issue by providing an intermediary layer between cloud consumers and cloud resources. Standardization appears to be a good solution to address interoperability issue. Cloud API defines a set of clear and easy to understand web services interfaces, through which cloud consumers are able to create and manage cloud resources in a unified way [21]. 


\section{CONCLUSION AND FUTURE WORK}

There are many new technologies emerging at a rapid rate, each with technological advancements and with the potential of making human's lives easier. Cloud Computing is also the feature of Service Computing [25]. Cloud Computing is now firmly established in the information technology landscape and its security risks need to be mapped and addressed at this critical stage in its development. There is a clear need for the standardization of current cloud platforms at least of terms of interface, negotiation and access through web services. Nimbus implements a number of front ends (e.g. Amazon EC2 and WSRF) to ensure access to their existing users. . Open Nebula used to adopt policies for resource management. It is also important to acknowledge the leadership and string presence of Eucalyptus and Xen. This paper represents a comprehensive comparison of different aspects of open source cloud platforms. In analysis of these various platforms the salient philosophical differences between them are found out. After this analysis user can better understand and can able to do better selection of cloud platform. As future work, more cloud solutions like apache VCL and anomaly are proposed for the comparison of the presented solutions through the performance evaluation.

\section{REFERENCES}

[1] Qi Zhang,LU Cheng,Raouf Boutaba:Cloud computing:State of-the-art and Research challenges: 20th April 2010,springer,Pp. 7-18.

[2] Monaco,Ania(7 june 2012[last update]),"A view inside the cloud", The institute.ieu.org(IEEE) retrieved august 21,2012 .

[3] Baburajan, rajani,"The rising cloud storage market opportunity strengthens vendors"

[4] Buyya Rajkumar,Karthik Sukumar: Platforms for building and deploying application for Cloud Computing,CSI Communication 2011

[5] Singh Tarry,Pavan Kumar Vara: Smart Metering the Clouds,IEEE International Workshops on Enabling Technologies,2009,pp. 66-71.

[6] Mc Hall,Tom:Gartner says worldwide software as a service revenue is forecast to grow 21 percent in 2011,gartner.com,28th july 2011

[7] Comparing Amazon's and google's platform-as a service(Paas) offerings/Enterprise web 2.0/ZD Net.com

[8] Sumit khurana and Anmol Gaurav verma,Comparision of ccloud computing service models: SaaS,PaaS,IaaS,IJECT,vol 4,april 2013

[9] J.J. Peng,X.J. Zhang,Z.Lei,et al , Comparison of several cloud computing platforms,Second International symposium on information science and engineering(ISISE '09),IEEE computer society,washington,Pp 23-27,2009.

[10] santosh kumar and R.H. Goudar: Cloud ComputingResearch Issues, challenges,Architecture,platforms and applications:A Survey,International journal of Future Computer and Communication, Vol. 1,Number 4,December 2012.

[11] Comparing Amazon's and Google's platform-as-aservice(PaaS) offerings IEnterprise web 2.0\ZDNet.com
[12] "Cloud Platform as a service(PaaS) in cloud computing Services”,Cloud sec.2011.Retrieved 2011-12-15.

[13] J.JPeng,X.J, Zhang,Z.Lei,B.F.Zhang and Q.Li,"Comparision of several cloud computing platforms",2009 second international symposium on Information Science and Engineering(ISISE '09).IEEE Computersociety,Washington,DC,USA,pp.23$27, \mathrm{DOI}=10.1109 / \mathrm{ICFN} .2010 .58$

[14] J.F.Yang and Z.B. Chen,"Cloud Computing Research and Security Issues," 2010 IEEE International conference on Computational Intelligence and Software Engineering(CISE), Wuhan pp.1-3,DOI=10-12 Dec. 2010

[15] T.Dillon,C.Wu,and E. Chang, "Cloud Computing: Issues and Challenges,"2010 24th IEEE International Conference on Advanced Information Networking and Applications(AINA),pp. 27-33,DOI=20-23 April 2010

[16] M.Q.Zhou,R. Zhang,W.Xie,W.N.Qian, and A. Zhou,"Security and privacy in cloud computing: A Survey", 2010 Sixth International Conference on Semantics,Knowledge and Grids(SKG),pp.105112,DOI=1-3 Nov.2010

[17] L Richardson,S Ruby.Restful Web services.O'Reilly.2007.

[18] David Bernstein,Nino Vidovic,Sohrab Modi: A cloud PaaS for highscale,Function and velocity Mobile Applications,International Conference on Systems and Networks Communications,2010.pp.117-123

[19] Nawsher Khan,A.Noraziah,Mustafa Mat Deris, and Elrasheed I.Ismail,Cloud Computing: Comparision of various Features,Springer,International Conference on Digital Enterprise and Information Systems,DEIS 2011,CCIS 194,pp.243-254.

[20] A.Cavoukian,Privacy and Digital Identity-Implepication for the Internet, Information and Pricaby commissioner of Ontario. 2008

[21] "SunMicrosystems Unveils open cloud platform",http://www.Sun.com/aboutSun/pr/200903/Sun flash.20090318.2.xml,2009

[22] Armbrust,M.,et al:Above the clouds:A Berkeley View Of Cloud Computing,Tech.Report No. UCB/EECS2009-28,2009.

[23] Vouk,Mladen A.,Cloud Computing-Issues, Research and Implementations,ITI08,pp.23-26-31,2008.

[24] IBM blue Cloud,http://www.ibm.com/grid/,Accessed on May 09,2011.

[25] Xiujuan Zhang,Guoqing Dong:A New Architecture of Online Trading Platform Based On Cloud Computing,Asia-Pacific Conference on Wearable Computing Systems, APWCS 2010,Shenzhen,China,IEEE Computer Society,Pp. 3235,2010 